\title{
Complex approach to monitoring athletes in the scope of overtraining prevention
}

\author{
Martina Bernaciková, Jan Novotný, Iva Burešová, Alena Žákovská
}

\begin{abstract}
The article introduces the issue of monitoring intensively training athletes who wish to avoid overtraining and want their training to be as effective as possible. The current definitions of overreaching and overtraining are addressed, together with the summary of causes, development and prevention of such conditions. The focus of the article is on the overview of relevant diagnostic methods including the latest non-invasive biochemical methods. The complex approach to the selection of psychological and physiological methods to establish the degree of the internal load of athletes is emphasised. A three-degree concept of athlete monitoring according to the demandingness and periodicity of diagnostic methods usage is presented.
\end{abstract}

Key words: Athletes, Monitoring, Fatigue, Overreaching, Overtraining, Overtraining syndrome, Heart Rate Variability, Profile of Mood States

\section{INTRODUCTION}

Overreaching is a permanent risk for athletes who train and compete. The negative impacts of the overreaching lie both in performance decline or stagnation and in health problems connected with more frequent injuries and overtraining syndrome. Meta-analytic study by Meeusen et al. (2013) collected important data on overtraining prevalence at $7-37 \%$ of athletes, mostly at endurance sports and disciplines.

Athletes and trainers should know and use instruments for overreaching detection in order to individually optimise the training process. The problem lies in the difficulty of establishing the current extent of the athlete training load which should not be exceeded.

\section{DEFINITION OF THE OVERREACHING AND OVERTRAINING}

The definitions of these conditions are not unified. According to the experts (Meeusen et al., 2013; Myrick, 2015; Soligard et al., 2016; Gazzano \& Gabbett, 2017) the relevant conditions are defined as follows:

Load is a combination of both sport and out of sport stimuli.

External load is an objectively measurable load (performance, work, distance, time) which is performed by the athlete in and outside the sport; it is and indicator of the working capacity of the athlete.

Internal load is an individual reaction of an athlete to the external load and other biological factors. It can be measured and expressed (e.g. with a heart rate, lactate concentration, subjective perception of the load); it stimulates training adaptation.

Overloading (OL) means a higher load, of a higher intensity, necessary for a sufficient physiological stimulation leading to a positive adaptation to the load

Acute fatigue is an imminent form of fatigue which develops already during the load and with enough rest lasts up to a few days. 
Overreaching (OR) - temporary (e.g. 2 weeks) signs of a complex fatigue from overreaching at a certain stage of the training (e.g. fatigue, decreased performance, bad mood). It is the initial stage of overtraining; the accumulation of this temporary fatigue leads to overtraining.

Functional overreaching, short-term (OR, FOR) is an accumulated training and out of training load leading to a short-term decline of the working capacity without any signs of physical or mental disorders. It requires a recovery lasting a few days or weeks.

Non-functional overreaching, extreme $(O R, N F O R)$ is an accumulated training and out of training load with an accentuated decline in working capacity and with signs of physical (hormonal) and mental (feeling tired) disorders. It requires a recovery lasting a few days or weeks.

The NFOR seems to create the border between the optimal load and negative overtraining.

Overtraining $(O T)$ - a long term process with repeated overreaching of the athlete, leading to the overtraining syndrome.

Overtraining syndrome (OTS) is a collection of pathophysiological and clinical problems which occur because of a lack of rest after extreme overreaching. These problems persist for several months. Burnout and staleness are used as synonyms.

The literature also uses the term Unexplained underperformance syndrome (UPS), which was introduced by British scientists dealing with fatigue diagnostics at the end of the last century. (Budgett, Newsholme \& Lehmann, 2000). Even though this term encompasses a wider definition and seems to be more suitable for the sport environment, it has not become widespread worldwide.

We tend to use the differentiation between and terminology for the individual stages of training loads and the development of overtraining as listed in Table 1. There are no clear boundaries between the stages.

Tab. 1: An overview of the extent of load and fatigue types (amended and completed according to (Meeusen et al., 2012; Myrick, 2015; Soligard et al., 2016; Gazzano \& Gabbett 2017)

\begin{tabular}{|l|c|c|c|c|c|}
\hline Training & $\begin{array}{c}\text { under- } \\
\text { training }\end{array}$ & training & optimal training & \multicolumn{2}{|c|}{ overtraining } \\
\hline Internal loading & $\begin{array}{c}\text { under- } \\
\text { loading }\end{array}$ & Overloading & $\begin{array}{c}\text { Functional } \\
\text { overreaching }\end{array}$ & $\begin{array}{c}\text { Non-functional } \\
\text { overreaching }\end{array}$ & $\begin{array}{c}\text { Overtraining } \\
\text { syndrome }\end{array}$ \\
\hline Work capacity & decreasing & increasing & $\begin{array}{c}\text { short-time } \\
\text { decreasing }\end{array}$ & decreasing & decreasing \\
\hline Fatigue & no fatigue & $\begin{array}{c}\text { acute } \\
\text { (short-time) }\end{array}$ & sub-chronic & \multicolumn{2}{|c|}{$\begin{array}{c}\text { chronic } \\
\text { (long-time) }\end{array}$} \\
\hline $\begin{array}{l}\text { Period of } \\
\text { recovery }\end{array}$ & - & days & days - weeks & weeks - months & more months \\
\hline Health state & - & \multicolumn{2}{|c|}{ good } & $\begin{array}{c}\text { malfunction } \\
\text { maladaptation }\end{array}$ & $\begin{array}{c}\text { serious } \\
\text { disease }\end{array}$ \\
\hline
\end{tabular}

\section{CAUSES, PREVENTION AND DEVELOPMENT OF OVERTRAINING}

The cause of overtraining is repeated non-functional overreaching without a sufficient recovery. It is a state of a long-term inadequate internal load of the athlete and his or her insufficient adaptation to the load. This situation leads to the decline in performance (2-3 months) without an apparent reason which might explain it. The inadequate performance is accompanied by several symptoms. These symptoms are diverse and highly individual which means that different athletes may show different symptoms. 
Both the inadequate training and other stressful factors such as work / school, home environment, family, team mates, pressure of competition, new sponsors, etc. are the causes of overtraining. It is thus the sum of all the stresses (including training) that an athlete must cope with (Halson \&Jeukendrup, 2004).

Causes and prevention of overtraining are illustrated in Fig. 1

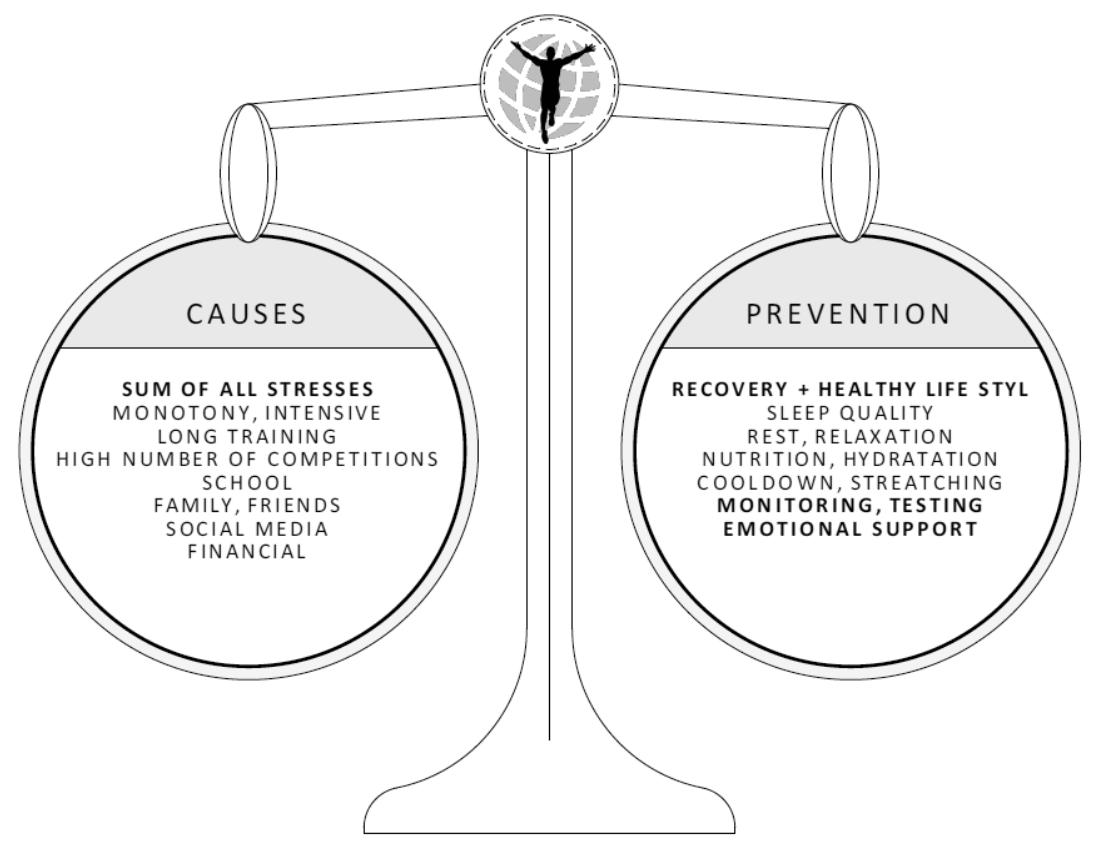

Fig. 1: Causes and prevention of overtraining (amended according to Jeukendrup, 2015).

The prevention of overtraining lies in the elimination of the causes, i.e. reducing the occurrence of non-functional overtraining. The training process needs to have an adequate loading and a sufficient recovery of the athlete, taking into consideration his or her current fatigue and load resistivity.

The prevention of overtraining requires the knowledge and ability to correctly use the tools for monitoring the current state of athletes (fatigue and load resistivity) - more information to follow. The basic tools for athletes and their trainers are training plans, training diaries and regular testing of athletes.

Development of overtraining is simplified in the following diagram (Fig. 2). 


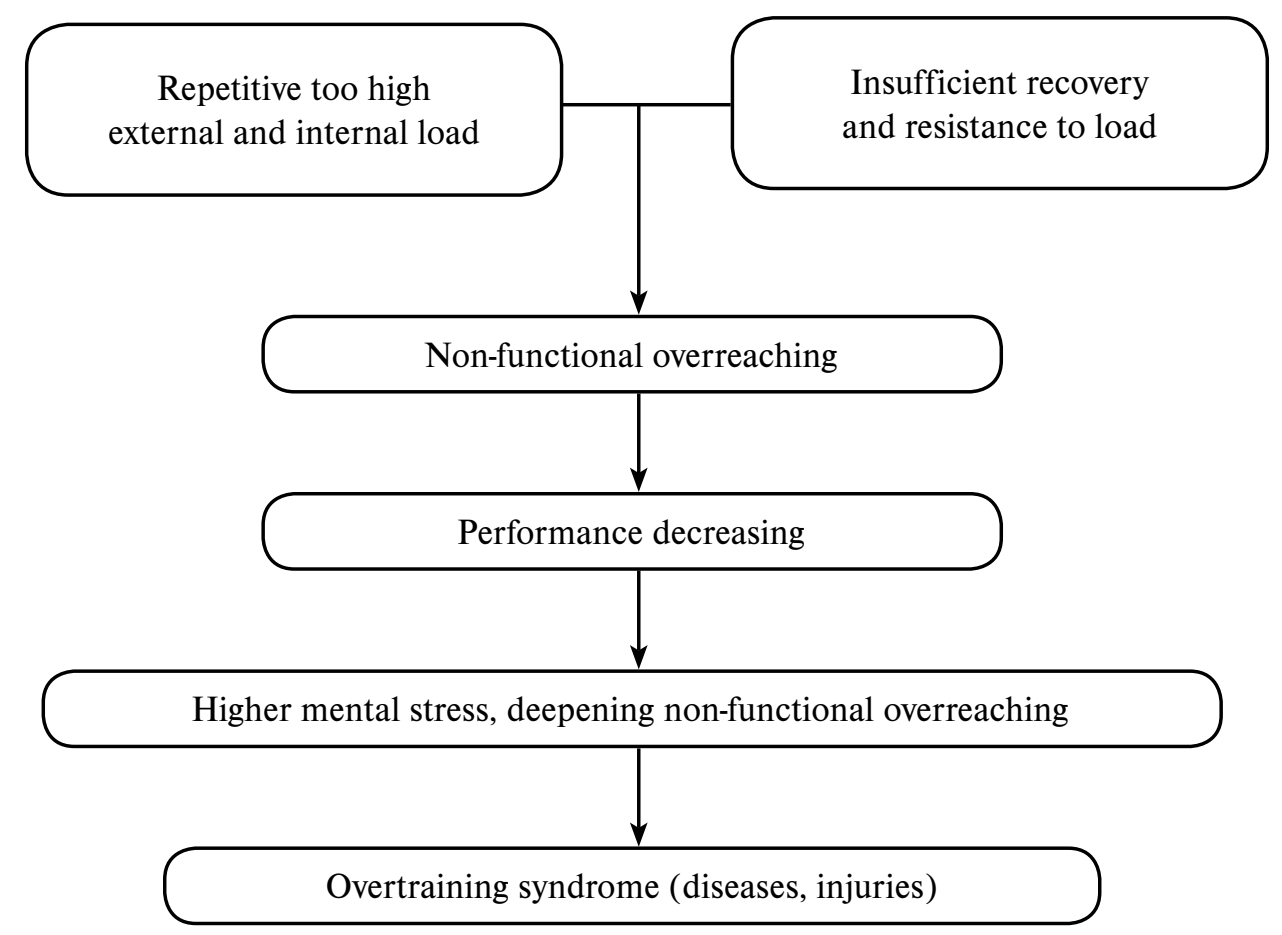

Fig. 2: Development of overtraining (based on Meuessen et al., 2012 and Gazzano \& Gabbett, 2017)

The most common symptoms of overtraining syndrome you can see in Tab 2. Parasympathetic Alternations is more common in aerobic sports and Sympathetic Alternations is more common in anaerobic sports. (Kreher \& Schwartz, 2012).

Tab. 2: Symptoms of overtraining syndrome (Kreher \& Schwartz, 2012).

\begin{tabular}{|l|l|l|}
\hline Parasympathetic Alterations & Sympathetic Alternations & Other \\
\hline Fatigue & Insomnia & Anorexia \\
\hline Depression & Irritability & Weight loss \\
\hline Bradycardia & Agitation & Lack of mental concentration \\
\hline Loss of motivation & Tachycardia & Heavy, sore, stiff muscles \\
\hline & Hypertension & Anxiety \\
\hline & Restlessness & Awakening unrefreshed \\
\hline
\end{tabular}




\section{OVERREACHING AND OVERTRAINING DIAGNOSTICS}

Diagnostic methods for monitoring fatigue and internal load of an athlete can be divided for example into these three groups: dynamometric and ergometric, psychological and physiological (Tab. 3).

Tab. 3: Overview of diagnostic methods to detect athlete overreaching (Holzer, 2012; Meeusen et al., 2013; Thorpe, Atkinson, Drust \& Gregson, 2017, modified and amended)

\begin{tabular}{|l|l|l|}
\hline Groups of diagnostic methods & Specific diagnostic methods and tools \\
\hline \multirow{5}{*}{ Dynamometric and ergometric } & $\begin{array}{l}\text { Dynamometry, ergometry - field and laboratory measuring and analysis of } \\
\text { athlete performance }\end{array}$ \\
\hline \multirow{5}{*}{ Psychological } & Neuro-circulatory & $\begin{array}{l}\text { Evaluation of neural autonomic regulation by heart rate measuring and } \\
\text { and exertion, and of mental state and fatigue }\end{array}$ \\
\hline \multirow{4}{*}{ Physiological } & Cardiological & $\begin{array}{l}\text { Evaluation of cardiac functions by electrocardiograph and blood pressure } \\
\text { analysis }\end{array}$ \\
\cline { 2 - 3 } & Anthropologic & $\begin{array}{l}\text { Evaluation of body composition (e.g. by electro-impedance analysis, DEXA, } \\
\text { plethysmography) }\end{array}$ \\
\cline { 2 - 3 } & Spiroergometric & Evaluation of respiratory response to load during spiroergometry \\
\cline { 2 - 3 } & Biochemical & $\begin{array}{l}\text { Evaluation of energetic and mineral metabolism as well as markers of tissue } \\
\text { damage by analysis of body fluids (urine, blood, saline etc.) }\end{array}$ \\
\cline { 2 - 3 } & Immunological & Evaluation of immune functions by blood analysis \\
\cline { 2 - 3 } & Haematological & $\begin{array}{l}\text { Evaluation of blood cells state and blood functions by microscopic and } \\
\text { biochemical analyses }\end{array}$ \\
\hline
\end{tabular}

\section{Dynamometry and ergometry}

These methods provide information about the current working capacity of an athlete. A significant decrease in the capacity is a symptom of fatigue. The methods can be simple and affordable, e.g. manual dynamometry, jump and bicycle ergometry. Strength, performance, work, height of jump, etc. are among measured and evaluated indicators. These tests are not able to distinguish between acute and chronic fatigue. Chronic fatigue might be considered at decreased working capacity even after a long-term recovery. Then there might a problem of distinguishing it from the symptoms of detraining, though. Therefore, it is essential to employ psychological and physiological indicators of chronic fatigue.

\section{Psychological methods}

The simplest and fastest is a dialogue with the closest family members and the trainer. There is a risk, though, that an unprofessional approach might cause a lot of harm, e.g. huge stress and frustration due to too ambitious parents. That is the reason why standardised methods, mostly questionnaires, developed by experts - psychologists should be used.

Psychological questionnaires for detection of subjective experience and feelings of athletes - cramps, pain, activity, fatigue, stress, discomfort, moods, anxiety, fear, confusion, sleep quality, concentration, nervousness, social conflicts, etc. Questionnaires detecting the psychological state of athletes are not always able to satisfactorily distinguish whether the causes lie in sport or outside 
it (Meussen et al., 2013). When formulating questions, it is essential to use clear and easy to understand terms. To express the extent of the perception five- or six-degree scales are used.

- Rating of perceived exertion - (RPE) has been used as an indicator of internal load for a long time. A ten-degree scale is used for athletes (Foster, 1998). According to Gazzano and Gabbett (2017) the total amount of internal load is expressed as a product of RPE and time. Then a daily or weekly amount of this load, index of short-term load (amount of load in a week) and chronic load (a four-week average) and an index of the load monotonicity (the standard error of measurement of weekly load) can be calculated.

- Training Distress Scale (TDS; Grove et al., 2014) is a questionnaire with 19 items to detect exertion in the last 24 hours.

- Profile of Mood States (POMS; McNair et al., 1971; Terry, Lane, Lane \& Keohane 1999) is a standardised and internationally acknowledged questionnaire. It is used to profile emotion and mood states. It is popular in sport psychology as it is economical, fast and easy to administer. It is considered to be one of the most reliable tools for overtraining detection (Meeusen et al. 2013). Over-trained athletes score significant higher in negative moods compared to positive moods.

- Recovery Stress Questionnaire for Athletes (RESTQ-Sport; Kellmann \& Kallus, 2001) a widespectrum questionnaire for athletes to detect and evaluate the state of the athlete - general stress, emotional stress, social stress, conflicts/pressure, lack of energy, physical complaints with a six-degree scale.

- Performance Failure Appraisal Inventory (PFAI; Conroy, Willow \& Metzler, 2002) is a questionnaire to detect athlete's fear of failure which belongs to causes of overtraining. High values relate to a state of burnout (Gustafsson, Sagar, Stenlink, 2017).

- Daily Analyses of Life-Demands (DALDA; Rushall, 1990) assesses the response of an athlete to training. The questionnaire consists of two parts and contains 34 items and athletes choose from three degrees for each item. The questionnaire should be completed daily and is thus not very practical.

- Pitsburg sleeping quality index (PSQI; Buysse, Reynolds, Monhk, Berman \& Kupfer, 1989) this questionnaire evaluates the sleep quality, it is a simple screening method consisting of 9 self assessment items.

- Athlete Sleeping Screening Questionnaire (ASSQ; Samuels, James, Lawson \& Meeuwisse, 2016) is a newer tool for sleep quality evaluation for athletes.

Good applicability of TDS and POMS questionnaires in our conditions has been, for instance, evaluated by Burešová, Demlová \& Bartošová, (2016).

\section{Physiological methods}

Neuro-circulatory methods lie in the evaluation of neural autonomic system (ANS) by heart rate measuring and analysis at rest and during a stress test. Neural autonomic system regulation disorder appears during sub-chronic and chronic pathological fatigue. During initial phases of a long-term fatigue from overreaching it is first the sympathetic and then the parasympathetic system having the biggest influence.

- Heart rate evaluation (amended according to Máček et al, 2011). Right before, during and after a physical exercise the activity of the sympathetic neural system increases, together with HR. After the exercise HR decreases. The steepness of the HR decline depends on the intensity and amount of the preceding exercise. With greater fatigue and after substantial physical exercise HR decreases at a slower rate. If the fatigue persists until the following morning, the morning resting HR may be slightly higher. With persisting fatigue, a decline in the physical fitness indexes can be observed at step tests. Unusually higher HR at a certain load might also signal 
presence of an infectious or another inflammatory disease. On the contrary, unusually lower $\mathrm{HR}$ at rest or at a load may by a case of an ANS disorder with a prevalence of parasympathicotonia or a heart disease. Gradually (over a few months) developing bradycardia should be a consequence of an expected adaptation to the endurance load.

Some studies dispute the $\mathrm{HR}_{\text {rest }}$ monitoring as a suitable marker for overreaching diagnostics (Bosquet, Merari, Arvisais \& Aubert, 2008), but despite this there are still reports on morning rest heart rate $\left(\mathrm{HR}_{\text {rest }}\right)$ being a usable indicator of a current state of ANS with athletes (de Araújo et al., 2017). It seems $\mathrm{HR}_{\text {rest }}$ should not be condemned, even though it is mostly the HRV analysis being often used for these purposes (Bisschoff, Coetzee \& Esco, 2016).

- Heart rate variability analysis $(H R V)$ : Already introduced "classical" indicators of HRV, such as spectral performance and its density in the established frequency ranges, are a part of athlete monitoring in the scope of overreaching prevention (Makivić, Djordjević, Wilis, 2013; Novotný, 2013; Botek, Krejčí \& McKune, 2018). Athletes who are well-rested and well-adapted to the physical load, such as marathon runners, reach a high spectral performance in the HF range, which is an indicator of a higher parasympathetic activity at rest and after a load. Stejskal et al. (2002) has created a new method of evaluating HRV with associated indicators of spectral analysis from three 5-minute intervals at ortho-clinostatic test (lying - standing lying) - Overall Score (OS), Vagus Activity Index (VA), Sympathicus - Vagus Balance Index (SVB), Functional Age (FA). Botek et al. (2018) has added that based on his studies the first interval of lying could be shortened to 1 minute as it does not negatively influence the quality of results. Same author (Botek et al., 2018) also recommends time-domain parameters: Normal to Normal intervals (NN), Standard Deviation of all intervals (SDNN), Standard Deviation of the Average of NN intervals (SDANN), square Root of the Mean of the Squares of the Successive Differences between adjacent NN intervals (rMSSD).

\section{Biochemical, immunological and haematological methods}

In blood samples which are analysed, it is possible to detect substances which are markers of pathophysiological changes due to the load to athletes' bodies. (Halson, Lancaster \& Jeukendrup, 2003; Wyatt, Donaldson \& Brown, 2013; Lee et al., 2017), e.g.:

- Suppression or insufficiency of energetic catabolism ( $\downarrow$ maximal lactacidemia)

- Endocrinal suppression or insufficiency of adrenals at rest or after a load ( $\downarrow$ stress hormones - Adrenalin and Noradrenalin, Testosterone, Cortisol)

- Immunosuppression ( $\downarrow$ Leukocytes, $\downarrow$ immunoglobulins IgG, IgA, IgM, Interferons, C-reactive protein, Interleukin 6)

- Erythrocyte damage ( $\downarrow$ Ery, Hb, Htc, $\downarrow$ Fe)

- Proteogenesis disorders ( $\downarrow$ essential amino acid Glutamine and its ratio to Glutamate)

- Muscle impairment, rhabdomyolysis (Myoglobin, Creatine kinase, Lactate-dehydrogenase)

Non-invasive biochemical methods: Methods which do not require unpleasant punctum to the athlete's body in order to get a blood sample are gradually developing (Lindsay \& Costello, 2017). These are analyses of other body fluids - saliva, urine, expiratory condensate or sweat. Correlations between plasma and saliva concentrations of Testosterone and Cortisol (Tanner, Nielsen, Allgrove, 2014) and between concentrations of lactate in blood and in expiratory condensate (Marek, Volke, Hawener, Mückenhoff \& Marek, 2010) have been discovered. The dynamics of the lactate concentrations in saliva probably corresponds the changes of the lactate in blood. It is possible to establish the lactate threshold by saliva analysis (Bocanegra, Diaz, Teixeira, Soares \& Espindola, 2012). 


\section{Complex approach to overtraining diagnostics}

The attributes of a complex approach are as follows:

- A rational selection and combination of diagnostic methods (tab. 3) for evaluation of external and internal load of an athlete.

- When evaluating the external load all stress factors should possibly be detected - from the domain of sports (realised training, competition performance, trainer's activity) and from the out-of-sport domain (school or work load, parents, other social challenges) .

- When evaluating the internal load, sufficiently sensitive and if possible non-invasive psychological and physiological methods for monitoring should be used.

- Periodicity of monitoring.

\section{Three-degree monitoring and overtraining diagnostics concept}

Diagnostic methods can be categorised into three degrees according to their demands on athletes, demands on results processing and the speed of their applicability and according to instrument and financial resources availability:

- Degree I - simple unexacting methods which do not inconvenience athletes and provide applicable results for training regulation instantly: RPE (after training), morning rest HR. Periodicity: once a day.

- Degree II - more complex methods which inconvenience athletes only to a small extent and provide results quickly: short psychological questionnaires (e.g. POMS, TDS), HRV analysis during a tilt test. Periodicity: once to three times a week according to the method and demand.

- Degree III - more exacting methods which put an adequate strain on athletes and provide results usually within three days: Longer psychological questionnaires (TESTQ-Sport, biochemical and immunological methods of saliva analysis). Periodicity: one a month or according to the demand.

If the degree I result provides a suspicion that there might be overreaching or overloading, a degree II test should be conducted. If positive results are obtained, a degree III method should be used and demanding training should be avoided. When the suspicion is confirmed, the athlete should be referred to a sport medicine physician and all training should be suspended until then.

We will verify the validity and reliability of the proposed diagnostic model in upcoming projects.

\section{CONCLUSION}

A satisfactory performance of an athlete is a result of an optimal training with regulated load without a counterproductive impact of non-functional overreaching and overtraining. The internal load of an athlete depends on the external load and other stress factors. Its rate should be adequate to the degree of the athlete adaptation to the load.

This requires a systematic monitoring of fatigue indicators, or physiological disorders in the body of athletes respectively.

For this purpose, we recommend a complex monitoring with a combination of psychological and physiological methods, which are, for practical reasons, categorised into three degrees, according to their demandingness and periodicity. The development of this concept at the Faculty of Sports Studies of the Masaryk University is a part of the project MUNI/51/05/2018. 


\section{References}

de Araújo, J. A., Queiroz, M. G., Novelli, F. I., de Jesus Lima de Sousa, L. C., Tricot, G. K., Lourenço Dias, A. R., ...Lucieli Teresa Cambri, L. T. (2017). Aerobic fitness influences rest and heart rate recovery on young men regardless of body mass index. Sport Sciences for Health, 13(1), 217-223.

Bisschoff, Ch. A., Coetzee, B. \& Esco, M. R. (2016). Relationship between Autonomic Markers of Heart Rate and Subjective Indicators of Recovery Status in Male, Elite Badminton Players. Journal of Sports Science and Medicine, 15(4), 658-669.

Bocanegra, O. L., Diaz, M. M., Teixeira, R. R., Soares, S. S. \& Espindola, F. S. (2012). Determination of the lactate threshold by means of salivary biomakers: chromogranin A as novel marker of exercise intensity. Eur J Appl Physiol, 112, 3195-3203.

Bosquet, L., Merkari, S., Arvisais, D. \& Aubert, A. E. (2008). Is heart rate a convenient tool to monitor over-reaching? A systematic review of the literature. British Journal of Sports Medicine, 42, 709-714.

Botek, M., Krejčí, J. \& McKune, A. J. (2018). Variabilita srdeční frekvence v tréninkovém procesu: historie, současnost a perspektiva. Olomouc: Univerzita Palackého v Olomouci.

Budgett R., Newsholme E., Lehmann M., et al. (2000). Redefining the overtraining syndrome as the unexplained underperformance syndrome. British Journal of Sports Medicine, 34: 67-68.

Burešová, I., Demlová, T. \& Bartošová, K. (2016). Coping strategies prefered byx adolescents when managing stress in sport - pilot study. The European Proceedings of Social and Behavioural Sciences. Future Academy: 240-254. (http:// dx.doi.org/10.15405/epsbs.2016.11.25).

Buysse, D. J., Reynolds, C. F., Monhk, T. H., Berman, S. R. \& Kupfer, D. J. (1989). The Pittsburgh Sleeping Quality Index: a new instrument for psychiatric practice and research. Psychiatry Res., 28(2), 19-213.

Conroy, D. E., Willow, J. P. \& Metzler, J. N. (2002). Multidimensional fear of failure measurement the performance failure appraisal inventory. J Appl Psychol, 14, 76-90.

Foster, C. (1998). Monitoring training in athletes with reference to overtraining syndrome. Med Sci Sports Exerc, 30(7), 1164-1168.

Gazzano, F. \& Gabbett T. (2017). A practical guide to workload management and injury prevention in college and high school sports. NSCA Coach, 4 (4), 30-35.

Grove, J. R., Main, L. C., Partridge, K., Bishop, D., Russel, S., Shepherdson, A., \& Ferguson, L. (2014). Training distress and performance readiness: Laboratory and field validation of a brief self-report measure. Scandinavian Journal of Medicine and Sicience in Sports, 24, 483-490.

Gustafsson, H., Sagar, S. S. \& Stenlink, A. (2017). Fear of failure, psychological stress, and burnout among adolescent athletes competing in high level sport. Scand J Med Sports, 27, 2091-2102.

Halson, S. L. \& Jeukendrup, A. E. (2004). Does overtraining exist? An analysis of overreaching and overtraining research. SportsMed, 34(4), 967-981.

Halson, S. L., Lancaster, G. I., Jeukendrup, A. E. \& Gleeson, M. (2003). Immunological responses to overreaching in cyclists. Medicine and Science in Sports and Exercise, 35(5), 854-861.

Holzer, K. (2012). The tired athlete. In: Brukner P. \& Khan K. (eds.). Clinical Sports Medicine. Sydney: The Mc Graw-Hill Co: $1118-1131$.

Jeukendrup, A. (2015). Causes and prevention of overtraining. Retrieved from http://www.mysportscience.com/singlepost/2015/03/08/Causes-and-prevention-of-overtraining.

Kellman, M. \& Kallus, K. W. (2001). The Recovery - Stress Questionnaire for Athletes: User manual. Champaign, IL: Human Kinetics.

Kreher, J. B. \& Schwartz, J. B. (2012). Overtraining Syndrome: A Practical Guide. Sports Health, 4 (2), 128-138.

Lee, E. C., Fragala, M. S., Kavouras, S. A., Queen, R. M., Pryor, J. L. \& Casa, D. J. (2017). Biomarkers in sports and exercise: Tracking heatlh, performance, and recovery in athletes. Journal of Strength and Conditioning Research, 31(10), 2920-2937.

Lindsay, A. \& Costello, J. T. (2017). Realising the potencial of urine and saliva as diagnostic tools in sport and exercise medicine. Sports Med, 47, 11-31.

Máček, M., Radvanský, J., Brůnová, B., Dad’ová, K., Fajstavr, J., Kolář, P., ... Zeman, V. (2011). Fyziologie a klinické aspekty pohybové aktivity. Praha: Galén.

Main, L. \& Grove, J. R. (2009). A multi-component assessment model for monitoring training distress among athletes. Eur J Sport Sci 2009; 9:195-202.

Makivić, B., Djordjević, M. \& Willis, M. S. (2013). Heart rate variability (HRV) as a tool for diagnostic and monitoring performance in sport and physical activities. J Exerc Physiology, 16(3), 103-131.

Marek, E. M., Volke, J., Hawener, I., Mückenhoff, K. \& Marek, W. (2010). Measurements of lactate in exhalted breath condensate at rest and after maximal exercise in young and healthy subjects. J Breath Res, 4, 017105 (8 pp).

Meeusen, R., Duclos, M., Foster, C., Fry, A., Gleeson, M., Nieman, D., ... Urhausen, A. (2013). Prevention, diagnosis and treatment of the overtraining syndrome: Joint consensus statement of the European College of Sport Science (ECSS) and the American College of Sports Medicine (ACSM). European Journal of Sport Science, 13(1), 1-24.

Morgan, W., Brown, D., Raglin, J., O'Connor, P. \& Ellickson, K. (1987). Psychological monitoring of overtraining and staleness. Br J Sports Med, 21, 107-114.

Myrick, K. M. (2015). Overtraining and Overreaching. Syndrome in Athletes. The Journal for Nurse Practitioners, 11 (10), 1018-1022. 
Novotný, J. (2013). Biologické ukazatele odezvy a adaptace na zátěž, únavy a regenerace sil. In: Kolektiv autorů. Regenerace a výživa ve sportu. Brno: Fakulta sportovních studií MU.

Rushall, B. S. (1990). A tool for measuring stress tolerance in elite athletes. Applied Sport Psychology, 2, 51-66.

Samuels, C. H., James, L., Lawson, D. \& Meeuwisse, W. (2015). The Athlete Sleeping Screening Questionnaire: a new toll for assessing and managing sleep in elite athletes. Br J Sports Med, 50, 418-422.

Soligard, T., Schwellnus, M., Alonso, J. M., Bahr, R., Clarsen, B., Dijkstra, H. P., ... Engebretsen, L. (2016). How much is too much? (Part 1) International Olympic Committee consensus statement on load in sport and risk of injury. British Journal of Sports and Medicine, 50(17), 1030-1041.

Stejskal, P., Šlachta, R., Elfmark, M., Salinger, J. \& Gaul-Aláčová, P. (2002). Spectral analysis of heart rate variability: New evaluation method. Acta Universitatis Palackianae Olomucencis Gymnica, 32 (2), 13-18.

Tanner, A. V., Nielsen, B. V. \& Allgrove J. (2014). Salivary and plasma cortisol and testosterone responses to interval and tempo runs and a bodyweight-only circuit session in endurance-trained men. Journal of Sports Sciences, 32(7), 680-689.

Terry, P. C., Lane, A. M., Lane, H. J., \& Keohane, L. (1999). Development and validation of a mood measure for adolescents. Journal of Sports Sciences, 17, 861-872.

Thorpe, R. T., Atkinson, G., Drust, B. \& Gregson W. (2017). Monitoring fatigue status in elite team-sport athletes: Implications for practise. International Journal of Sports Physiology and Performance, 12(2), 27-35.

Wyatt F. B., Donaldson A. \& Brown E. (2013). The Overtraining Syndrome: A Meta-Analytic Review. Journal of Exercise Physiologyonline, 16(2), 12-23. 